\title{
Nonseminomatous germ cell tumors: Assessing the need for postchemotherapy contralateral pulmonary resection in patients with ipsilateral complete necrosis
}

\author{
Benjamin Besse, MD, PhD, ${ }^{\mathrm{a}}$ Dominique Grunenwald, MD, ${ }^{\mathrm{b}}$ Aude Fléchon, MD, $\mathrm{PhD},{ }^{\mathrm{c}}$ Armelle Caty, $\mathrm{MD},{ }^{\mathrm{d}}$ \\ Christine Chevreau, MD, ${ }^{\mathrm{e}}$ Stéphane Culine, $\mathrm{MD}, \mathrm{PhD},{ }^{\mathrm{f}}$ Christine Théodore, $\mathrm{MD},{ }^{\mathrm{g}}$ and Karim Fizazi, $\mathrm{MD}, \mathrm{PhD}{ }^{\mathrm{a}}$
} Objectives: Our objective was to explore the pathologic components of residual masses after primary chemother-
apy in patients with metastatic nonseminomatous germ cell tumors.

\begin{abstract}
Methods: A multicenter retrospective study was conducted of 71 patients with thoracic residual masses (39 patients had bilateral lung metastasis) after first-line cisplatin-based chemotherapy for disseminated nonseminomatous germ cell tumors. Among the 71 patients, 52 also had a retroperitoneal lymph node dissection.

Results: Pathologic findings in postchemotherapy residual masses included complete necrosis, teratoma, and viable cancer in $31 \%, 55 \%$, and $14 \%$ of patients, respectively. Discordant pathologic findings were evidenced between retroperitoneal lymph node and thoracic (lung or mediastinal lymph nodes) residual masses in $27 \%$ of patients. When a bilateral pulmonary resection was performed, only $2(5 \%)$ of 39 patients had discordant histologic findings between the two lungs. Among patients who had necrosis only in residual masses from their first lung $(\mathrm{n}=20), 19(95 \%)$ also had necrosis only in contralateral lesions. A single patient had necrosis only in the first lung and some teratoma in the contralateral lung.
\end{abstract}

Conclusions: This report shows a high rate $(95 \%)$ of pathologic concordance between the two lungs. Avoiding contralateral lung surgery could therefore be considered when complete necrosis is found in the first lung after induction chemotherapy for nonseminomatous germ cell tumor.

Multimodality treatments combining cisplatin-based chemotherapy and surgery cure about $80 \%$ of patients with advanced nonseminomatous germ cell tumor (NSGCT). ${ }^{1}$ Guidelines promote tailoring induction chemotherapy to the prognostic groups identified in the International Germ Cell Consensus Classification (IGCCCG) and using serum tumor markers to monitor its efficacy. ${ }^{2,3}$ At normalization of serum tumor markers after chemotherapy, about one third to one half of patients have residual masses at radiologic assessment. The largest surgical studies have shown that residual masses contain viable tumor cells and teratoma in $12 \%$ to $15 \%$ and $34 \%$ to $42 \%$ of cases, respectively. ${ }^{4-13}$ Moreover, comparative pathologic analysis of retroperitonal lymph node dissection (RPLND) specimens and lung metastases has unveiled a discordance in lesion components in $28 \%$ to $36 \%$ of cases ${ }^{8,11,13,14}$ Complete necrosis is found in residual lung masses in a relatively high proportion of

From the Institut Gustave Roussy, Villejuif ${ }^{\mathrm{a}}$; Hôpital Tenon, Paris ${ }^{\mathrm{b}}$; Centre Léon Bérard, Lyon $^{\text {c; }}$ Centre Oscar Lambret, Lille ; Institut Claudius Regaud, Toulouse ${ }^{\mathrm{e}}$; Centre Val d'Aurelle Paul-Lamarque, Montpellier; and Hôpital Foch, Suresnes ${ }^{\mathrm{g}}$; France. Read in part at the Forty-first Annual Meeting of the American Society of Clinical Oncology, Orlando, Fla, May 13-17, 2005.

Received for publication Oct 23, 2007; revisions received Aug 15, 2008; accepted for publication Sept 12, 2008.

Address for reprints: Karim Fizazi, MD, PhD, Chairman of the Genito-Urinary Group, Department of Medicine, Institut Gustave Roussy, 39 rue Camille Desmoulins, 94805 Villejuif, France (E-mail: fizazi@igr.fr).

J Thorac Cardiovasc Surg 2009; 137:448-52

$0022-5223 / \$ 36.00$

Copyright (c) 2009 by The American Association for Thoracic Surgery doi:10.1016/j.jtcvs.2008.09.032 patients, ranging from $54 \%$ to $71 \%$, after normalization of serum tumor markers after chemotherapy. ${ }^{8,11,13,14}$ Extensive resection of all residual masses is therefore currently recommended by most authors. However, in this setting, surgical complications range from $6 \%$ for an isolated lung metastasis and $8 \%$ for an isolated RPLND to $13 \%$ for mediastinal resection or $35 \%$ for a sequential RPLND and thoracic resection. ${ }^{15-18}$ use and the cumulative dose of bleomycin were shown to be correlated with increased lung surgery-related morbidity and mortality, particularly in patients requiring major pulmonary resections. ${ }^{19}$

This prompted our decision to conduct this retrospective study of patients with metastatic NSGCT after normalization of tumor markers to (1) confirm the discrepancy of histologic findings between thoracic and retroperitoneal residual masses, (2) correlate histologic findings in mediastinal lesions with those found in retroperitonal or lung lesions, due to the lack of published data, ${ }^{14}$ and (3) compare histologic findings between ipsilateral and contralateral lung lesions to determine whether contralateral lung surgery is necessary when necrosis only is found in postchemotherapy residual lung masses.

\section{METHODS AND PATIENTS}

This is a French multicenter retrospective study. Eligibility criteria included the following: male patients treated consecutively from January 1980 to January 2003, histologically proven metastatic NSGCT (or the diagnosis based on elevated serum markers and a presentation compatible with a metastatic germ cell tumor [GCT]), first-line cisplatin-based chemotherapy, and evidence of residual masses after first-line chemotherapy: (1) 


\section{Abbreviations and Acronyms \\ $\mathrm{CI}=$ confidence interval \\ $\mathrm{GCT}=$ germ cell tumor \\ IGCCCG $=$ International Germ Cell Consensus Classification \\ NSGCT $=$ nonseminomatous germ cell tumor \\ OS = overall survival \\ PFS = progression-free survival \\ RPLND = retroperitonal lymph node dissection}

thoracic (either lung or mediastinal lymph node metastases) and retroperitoneal masses or (2) bilateral thoracic lesions. Patients with metastatic primary mediastinal tumors were not included. In addition, normalized serum tumor markers, including alfa-fetoprotein (AFP), human chorionic gonadotropin (HCG), and lactate dehydrogenase (LDH) in all cases, were required at the time of postchemotherapy surgery. Surgical management could include partial or complete excision of residual masses and, if reoperation was performed, the interval between the two operations had to be less than 4 months. No additional chemotherapy was allowed between the first and last resections. Patients with residual viable NSGCT containing malignant non-GCT neoplasms such as sarcoma and adenocarcinoma, usually called “teratoma with malignant transformation,", ${ }^{, 2}$ were included in this study. Investigators were asked to provide pathologic data on the primary tumor, the prognostic group according to the IGCCCG classification, ${ }^{21}$ the type of first-line chemotherapy, postchemotherapy normalization of serum tumor markers, sites concerned by postchemotherapy surgery, pathologic analysis of residual masses, surgery-related mortality, follow-up information including data on relapse and survival, and the incidence of the growing teratoma syndrome. ${ }^{22}$ Data collection was finalized in July 2004. Shrinkage was calculated as the percentage of change in the maximum diameter of a mass. The model developed by Steyerberg and associates, ${ }^{11}$ which identifies subgroups of patients with a high probability of necrosis, was applied in this series. Progression-free survival (PFS) was defined as the time from randomization until objective tumor progression or death. PFS and overall survival (OS) rates were estimated by the Kaplan-Meier method. For the analysis of survival, follow-up started on the date of postchemotherapy surgery. This research was conducted within the framework of the Internal Review Board (Commission Scientifique des Essais Thérapeutiques de l'Institut Gustave Roussy).

\section{RESULTS}

\section{Patient Characteristics and Treatment}

Five institutions participated in the study. Seventy-one patients fulfilling study criteria were recruited over a 23year period. Patient characteristics and first-line chemotherapy regimens are listed in Table 1 . The median number of chemotherapy cycles was 4 (range 3-12). Tumor markers had normalized after the first regimen in $57(80 \%)$ patients. The first surgical resection of residual masses was performed after a median period of 44 days after chemotherapy (range $10-121$ days). Fifty (70\%) and $11(15 \%)$ patients underwent a second and a third resection after a median period of 47 and 41 days, respectively. Surgical procedures are summarized in Figure 1. Fifty-two (73\%) patients underwent both RPLND and a thoracotomy, including 29 who had a resection of pulmonary metastases, 16 who had a resec-
TABLE 1. Patient characteristics

\begin{tabular}{|c|c|c|}
\hline \multirow[b]{2}{*}{ Characteristics } & \multicolumn{2}{|c|}{ Patients $(n=71)$} \\
\hline & No. & $\%$ \\
\hline \multicolumn{3}{|l|}{ Age, y } \\
\hline Median & 26.8 & \\
\hline Range & $17-43$ & \\
\hline \multicolumn{3}{|l|}{ Primary tumor site } \\
\hline Testis & 67 & 94 \\
\hline Retroperitoneum & 4 & 6 \\
\hline \multicolumn{3}{|c|}{ Pathologic components in the primary tumor } \\
\hline Seminoma & 7 & 10 \\
\hline Embryonal carcinoma & 45 & 63 \\
\hline Yolk sac tumor & 30 & 42 \\
\hline Choriocarcinoma & 26 & 37 \\
\hline Teratoma & 37 & 52 \\
\hline Immature teratoma & 21 & 30 \\
\hline Other & 1 & 1 \\
\hline \multicolumn{3}{|c|}{ Serum markers prior to initial chemotherapy } \\
\hline \multicolumn{3}{|c|}{ HCG, IU/L } \\
\hline Median & 277,5 & \\
\hline Range & $0-1,000,000$ & \\
\hline Missing values & 6 & 8 \\
\hline \multicolumn{3}{|l|}{$\mathrm{AFP}, \mathrm{ng} / \mathrm{mL}$} \\
\hline Median & 106 & \\
\hline Range & $0-40,927$ & \\
\hline Missing values & 4 & 6 \\
\hline \multicolumn{3}{|l|}{ LDH, IU/L } \\
\hline Median & $1.88 \mathrm{~N}$ & \\
\hline Range & $0-26 \mathrm{~N}$ & \\
\hline Missing values & 18 & 25 \\
\hline \multicolumn{3}{|l|}{ IGCCCG } \\
\hline Favorable & 17 & 30 \\
\hline Intermediate & 15 & 27 \\
\hline Poor & 24 & 43 \\
\hline Missing data & 15 & \\
\hline \multicolumn{3}{|l|}{ First-line chemotherapy regimen } \\
\hline BEP & 48 & 67 \\
\hline EP & 7 & 10 \\
\hline Other & 16 & 23 \\
\hline
\end{tabular}

$A F P$, Alfa-fetoprotein; $B E P$, etoposide, cisplatin, bleomycin; $E P$, etoposide, cisplatin; $H C G$, human chorionic gonadotropin; IGCCCG, International Germ Cell Consensus Classification; $L D H$, lactate dehydrogenase.

tion of mediastinal lymph nodes, and 7 who had both operations. Resection of bilateral lung lesions and mediastinal lymph node metastases was achieved in 39 and 28 patients, respectively. Bilateral lung surgery was performed by sternotomy in 4 patients and bilateral thoracotomies in 34 patients (missing data for 1 patient). Bilateral thoracotomies were sequential in 25 patients (median time between operations was 13 days), whereas it was performed during the same procedure in 9 patients.

\section{Pathology}

Pathologic findings in residual lesions included complete necrosis, teratoma, immature teratoma, and viable cancer in $31 \%, 39 \%, 16 \%$, and $14 \%$ of patients, respectively. The 


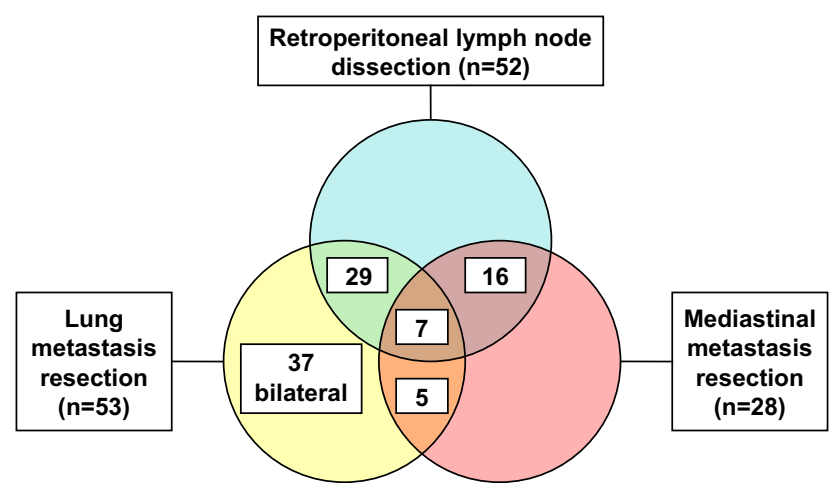

FIGURE 1. Distribution of surgical procedures among the $71 \mathrm{pts}$ included.

pathologic discordance are listed in Table 2 and the pathological discordances are summarized in Figure 2. The overall rate of pathologic discordance (complete necrosis vs teratoma vs viable cancer) between retroperitoneal lymph node and thoracic (lung or mediastinal lymph nodes) residual masses was $27 \%(n=14 / 52)$. In patients who had both a resection of lung metastases and RPLND $(n=36)$, the discordance rate was $33 \%(n=12)$. The more aggressive pathologic component was found in the retroperitoneal lymph nodes in $9(25 \%)$ patients and in the lung in $3(8 \%)$ patients. Among 15 patients who had complete necrosis in retroperitoneal lymph nodes, pathologic findings in their lung metastases were as follows: complete necrosis $(\mathrm{n}=12,80 \%)$, teratoma $(\mathrm{n}=2)$, and cancer cells $(\mathrm{n}=1)$. In patients who underwent resection of both mediastinal and retroperitoneal lymph nodes $(\mathrm{n}=23)$, the discordance rate was $17 \%(\mathrm{n}=$ 4); the more aggressive pathologic component was found in the retroperitoneal lymph nodes in 3 patients. Pathologic findings were discordant in $4(33 \%)$ of 12 patients who underwent resection of both mediastinal lymph nodes and pulmonary metastases.

In contrast, only $2(5 \%)$ of the 39 patients who underwent a resection of ipsilateral and contralateral pulmonary metastases had discordant pathologic findings between the two lungs. The first of these 2 patients was classified in the good prognostic group according to IGCCCG and was treated with 4 cycles of cisplatin and etoposide. Metastases from both lungs contained teratoma, but only pulmonary metastases located in the right lung also contained yolk sac tumor. The second patient was treated with 4 cycles of cisplatin, bleomycin, and etoposide followed by high-dose chemotherapy for an intermediate prognosis NSGCT. The pathologic examination of residual masses found complete necrosis in retroperitoneal and mediastinal lymph nodes and also in the pulmonary metastases located in the right lung, whereas the contralateral lung also contained some teratoma. Among 20 patients who had complete necrosis in the residual masses in the first operated lung, $19(95 \%)$ also had complete necrosis in the residual masses from the contralateral lung.
TABLE 2. Tumor characteristics and pathologic analyses of residual pulmonary masses

\begin{tabular}{|c|c|c|c|c|c|c|c|c|}
\hline & \multicolumn{2}{|c|}{ Necrosis } & \multicolumn{2}{|c|}{ Teratoma } & \multicolumn{2}{|c|}{ Cancer } & \multicolumn{2}{|c|}{ Total } \\
\hline & No. & $\%$ & No. & $\%$ & No. & $\%$ & No. & $\%$ \\
\hline \multicolumn{9}{|c|}{ Primary tumor histology } \\
\hline Teratoma negative & 9 & 36 & 12 & 48 & 4 & 16 & 25 & 50 \\
\hline Teratoma positive & 17 & 68 & 4 & 16 & 4 & 16 & 25 & 50 \\
\hline \multicolumn{9}{|l|}{$\begin{array}{l}\text { Prechemotherapy AFP } \\
\text { (ng/mL) }\end{array}$} \\
\hline Normal & 5 & 50 & 3 & 30 & 2 & 20 & 10 & 24 \\
\hline Elevated & 16 & 50 & 9 & 28 & 7 & 22 & 32 & 76 \\
\hline \multicolumn{9}{|l|}{$\begin{array}{l}\text { Prechemotherapy HCG } \\
\text { (IU/L) }\end{array}$} \\
\hline$<1,000$ & 13 & 45 & 11 & 38 & 5 & 17 & 29 & 61 \\
\hline $1,000-10,000$ & 2 & 40 & 1 & 20 & 2 & 40 & 5 & 10 \\
\hline$>10,000$ & 14 & 100 & 0 & 0 & 0 & 0 & 14 & 29 \\
\hline \multicolumn{9}{|l|}{ IGCCCG } \\
\hline Good & 3 & 23 & 8 & 62 & 2 & 15 & 13 & 33 \\
\hline Intermediate & 6 & 67 & 2 & 22 & 1 & 11 & 9 & 22 \\
\hline Poor & 16 & 84 & 1 & 5 & 2 & 11 & 19 & 45 \\
\hline \multicolumn{9}{|l|}{ Steyerberg score } \\
\hline$>95 \%$ necrosis & 13 & 100 & 0 & 0 & 0 & 0 & 13 & 24 \\
\hline \multicolumn{9}{|l|}{ Histology at RPLND } \\
\hline Necrosis & 12 & 80 & 2 & 13 & 1 & 7 & 15 & 47 \\
\hline Teratoma & 5 & 42 & 7 & 58 & 0 & 0 & 12 & 38 \\
\hline Cancer & 4 & 44 & 2 & 22 & 3 & 33 & 9 & 28 \\
\hline \multicolumn{9}{|c|}{$\begin{array}{l}\text { Histology at contralateral } \\
\text { lung resection }\end{array}$} \\
\hline Necrosis & 19 & 95 & 1 & 5 & 0 & 0 & 20 & 51 \\
\hline Teratoma & 0 & 0 & 12 & 100 & 0 & 0 & 12 & 31 \\
\hline Cancer & 0 & 0 & 1 & 14 & 6 & 86 & 7 & 18 \\
\hline \multicolumn{9}{|l|}{ Shrinkage } \\
\hline \multicolumn{9}{|c|}{$\begin{array}{l}\text { Retroperitoneal lymph } \\
\text { nodes }\end{array}$} \\
\hline$\geq 50 \%$ & 8 & 80 & 2 & 20 & 0 & 0 & 10 & 59 \\
\hline$<50 \%$ & 8 & 47 & 6 & 35 & 3 & 18 & 17 & 41 \\
\hline \multicolumn{9}{|l|}{ Lung metastasis } \\
\hline$\geq 50 \%$ & 7 & 44 & 7 & 44 & 2 & 12 & 16 & 48 \\
\hline$<50 \%$ & 7 & 41 & 4 & 23 & 6 & 36 & 17 & 52 \\
\hline
\end{tabular}

$A F P$, Alfa-fetoprotein $H C G$, human chorionic gonadotropin; IGCCCG, International Germ Cell Consensus Classification; RPLND, retroperitonal lymph node dissection.

\section{Survival and Factors Predictive of Necrosis in Lung Lesions}

Survival. After a median follow-up of 5.6 years (range $0.6-19.7)$, the 5-year PFS was $65 \%$ (95\% confidence interval $[\mathrm{CI}], 59 \%-72 \%)$ and the 5 -year OS was $94 \%(95 \% \mathrm{CI}$, $91 \%-97 \%)$. Eleven $(15 \%)$ and $11(15 \%)$ patients had a recurrent malignant NSGCT and growing teratoma syndrome, respectively. Among the 39 patients with bilateral lung resection, 9 had recurrence including 4 with growing teratoma syndrome; site of recurrence was only lung in 3 patients, lung and other site in 3 patients, and others site in 2 patients (missing data for 1 patient). Of 16 patients with unilateral lung resection, none had contralateral residual nodules, 1 has a mediastinal recurrence, and 3 extrathoracic 


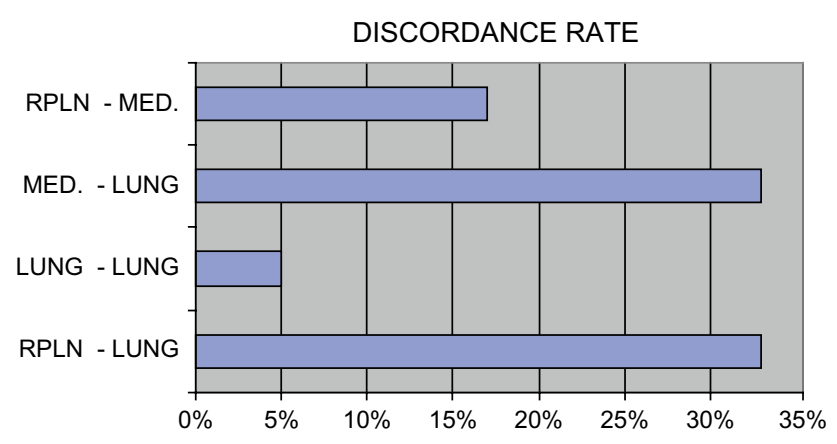

FIGURE 2. Pathological discordance rate among the residual sites. RPLN, Retroperitoneal lymph nodes; $M E D$., mediastinal lesions.

recurrences were observed. Four patients died, all of disease progression.

Shrinkage. Shrinkage was not correlated with OS or PFS. However, shrinkage was well correlated with the percentage of complete necrosis in retroperitoneal lymph nodes but not in lung metastases (Table 2).

Predictive model of complete necrosis. Among the 13 $(24 \%)$ patients who fit Steyerberg's subgroup criteria indicating a likelihood of complete necrosis in excess of $90 \%$ according to this model, complete necrosis was found in lung metastases in all cases (Table 2).

\section{DISCUSSION}

The discrepancy in pathologic findings between postchemotherapy residual retroperitoneal and pulmonary masses in patients with disseminated NSGCT has been extensively reported, and our results (a concordance rate of only 67\%) are consistent with previously published data. ${ }^{8,11,13,14}$ Although the numbers are too small to allow firm conclusions, postchemotherapy residual mediastinal lymph node masses seem to be quite similar to residual retroperitoneal masses with a pathologic concordance rate of $83 \%(95 \% \mathrm{CI}$, $61 \%-95 \%$ ), which contrasts with a pathologic concordance rate of only $67 \%(95 \% \mathrm{CI}, 35 \%-90 \%)$ for residual pulmonary masses. The similarity in pathologic findings between residual retroperitoneal and mediastinal masses is likely to be explained by the route of lymphatic drainage from the retroperitoneum directly into the visceral mediastinum via the thoracic duct. Although data in the literature are scarce and limited regarding pathologic findings between residual mediastinal and pulmonary masses, ${ }^{14,20,23}$ the discrepancy we found has previously been suggested. ${ }^{14}$

To our knowledge, no published study has focused specifically on the pathologic analysis of residual ipsilateral and contralateral lung masses; hitherto, only anecdotal cases have been reported. ${ }^{7,14}$ The high rate $(95 \% \mathrm{CI}, 83 \%-$ $99 \%, \mathrm{n}=39$ ) of pathologic concordance between residual masses from the two lungs found in this study is potentially an important finding given the alleged paucity of reports on the subject. Of 20 patients with complete necrosis in residual masses in the first lung, $19(95 \%)$ also had complete necrosis in residual masses in the contralateral lung. The practical consequences may include surveillance of the contralateral lung in such patients, rather than resection of contralateral masses, thus avoiding significant morbidity and allowing substantial cost savings.

Unfortunately, the models currently available to predict complete necrosis in residual lesions are not considered accurate enough. In a multicentric series of 215 patients with disseminated NSGCT and postchemotherapy residual masses, Steyerberg and associates ${ }^{11}$ identified subgroups of patients with a high likelihood of necrosis at thoracotomy. However, an attempt to validate this predictive model failed; only a 76\% complete necrosis rate was obtained in a series of 70 patients in whom the predicted probability of complete necrosis in residual pulmonary masses was $93 \% .{ }^{8}$ New methods are being investigated to predict pathologic findings in residual masses. The use of positron emission tomography with 2-(fluorine-18)-fluoro-2-deoxy-D-glucose has been investigated. Unfortunately, the absence of tracer uptake did not correlate with complete necrosis in $37 \%$ to $58 \%$ of cases in NSGCT. ${ }^{23,24}$ Gene expression profiling in NSGCT may be a useful tool for the selection of chemosensitive tumors, but it has not been validated in postchemotherapy residual masses. ${ }^{25}$

In conclusion, we found a $95 \%$ rate of pathologic concordance between residual ipsilateral and contralateral pulmonary masses after chemotherapy in patients with metastatic NSGCT. This result raises the question of surveillance alone, rather than a contralateral thoracotomy in patients in whom complete necrosis is found in residual masses from the first lung, to avoid unnecessary morbidity. We proposed a renewed algorithm for the surgical management of patients with metastatic NSGCT (Figure 3).

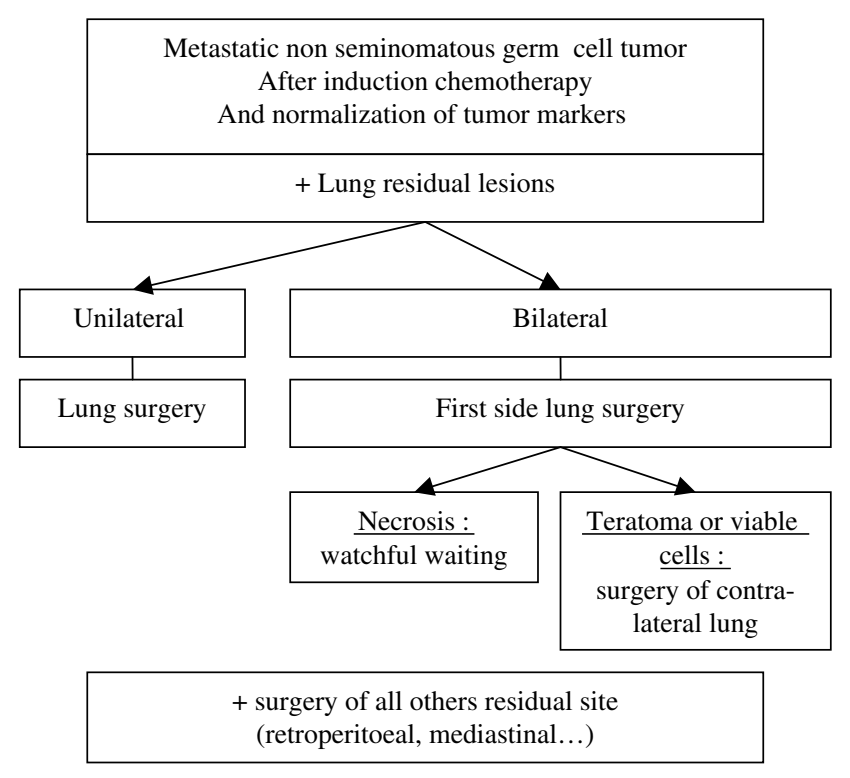

FIGURE 3. Proposed algorithm for residual lung lesions. 
We are indebted to Lorna Saint Ange for her editing assistance.

\section{References}

1. Bosl GJ, Motzer RJ. Testicular germ-cell cancer. N Engl J Med. 1997;337: 242-53.

2. Schmoll HJ, Souchon R, Krege S, Albers P, Beyer J, Kollmannsberger C, et al. European consensus on diagnosis and treatment of germ cell cancer: a report of the European Germ Cell Cancer Consensus Group (EGCCCG). Ann Oncol. 2004; 15:1377-99.

3. Fizazi K, Culine S, Kramar A, Amato RJ, Bouzy J, Chen I, et al. Early predicted time to normalization of tumor markers predicts outcome in poor-prognosis nonseminomatous germ cell tumors. J Clin Oncol. 2004;22:3868-76.

4. Fizazi K, Tjulandin S, Salvioni R, Germa-Lluch JR, Bouzy J, Ragan D, et al. Viable malignant cells after primary chemotherapy for disseminated nonseminomatous germ cell tumors: prognostic factors and role of postsurgery chemotherapyresults from an international study group. J Clin Oncol. 2001;19:2647-57.

5. Fizazi K, Oldenburg J, Dunant A, Chen I, Salvioni R, Hartmann JT, et al. Assessing prognosis and optimizing treatment in patients with postchemotherapy viable nonseminomatous germ-cell tumors (NSGCT): results of the sCR2 international study. Ann Oncol. 2008;19:259-64.

6. Fossa SD, Aass N, Ous S, Hoie J, Stenwig AE, Lien HH, et al. Histology of tumor residuals following chemotherapy in patients with advanced nonseminomatous testicular cancer. J Urol. 1989;142:1239-42.

7. Germa-Lluch JR, Garcia Dm X, Maroto P, Paz-Ares L, Arranz JA, Guma J, et al. Clinical pattern and therapeutic results achieved in 1490 patients with germ-cell tumours of the testis: the experience of the Spanish Germ-Cell Cancer Group (GG). Eur Urol. 2002;42:553-62.

8. McGuire MS, Rabbani F, Mohseni H, Bains M, Motzer R, Sheinfeld J. The role of thoracotomy in managing postchemotherapy residual thoracic masses in patients with nonseminomatous germ cell tumours. BJU Int. 2003;91:469-73.

9. Rasmussen OV, Daugaard G, Christiansen S, Sorensen BL, Rorth M. Secondary surgery in patients with malignant germ cell tumors. J Urol. 1992;147:393-7.

10. Steyerberg EW, Keizer HJ, Fossa SD, Sleijfer DT, Toner GC, Schraffordt KH, et al. Prediction of residual retroperitoneal mass histology after chemotherapy for metastatic nonseminomatous germ cell tumor: multivariate analysis of individual patient data from six study groups. J Clin Oncol. 1995;13:1177-87.

11. Steyerberg EW, Keizer HJ, Messemer JE, Toner GC, Schraffordt KH, Fossa SD, et al. Residual pulmonary masses after chemotherapy for metastatic nonseminomatous germ cell tumor. Prediction of histology. ReHiT Study Group. Cancer. 1997;79:345-55.

12. Steyerberg EW, Gerl A, Fossa SD, Sleijfer DT, de Wit R, Kirkels WJ, et al. Validity of predictions of residual retroperitoneal mass histology in nonseminomatous testicular cancer. J Clin Oncol. 1998;16:269-74.
13. Toner GC, Panicek DM, Heelan RT, Geller NL, Lin SY, Bajorin D, et al. Adjunctive surgery after chemotherapy for nonseminomatous germ cell tumors: recommendations for patient selection. J Clin Oncol. 1990;8:1683-94.

14. Hartmann JT, Candelaria M, Kuczyk MA, Schmoll HJ, Bokemeyer C. Comparison of histological results from the resection of residual masses at different sites after chemotherapy for metastatic non-seminomatous germ cell tumours. Eur $J$ Cancer. 1997;336:843-7.

15. Skinner DG, Melamud A, Lieskovsky G. Complications of thoracoabdominal retroperitoneal lymph node dissection. J Urol. 1982;127:1107-10.

16. Kesler KA, Brooks JA, Rieger KM, Fineberg NS, Einhorn LH, Brown JW. Mediastinal metastases from testicular nonseminomatous germ cell tumors: patterns of dissemination and predictors of long-term survival with surgery. J Thorac Cardiovasc Surg. 2003;125:913-23.

17. Tognoni PG, Foster RS, McGraw P, Heilman D, Bihrle R, Rowland RG, et al. Combined post-chemotherapy retroperitoneal lymph node dissection and resection of chest tumor under the same anesthetic is appropriate based on morbidity and tumor pathology. J Urol. 1998;159:1833-5.

18. Liu D, Abolhoda A, Burt ME, Martini N, Bains MS, Downey RJ, et al. Pulmonary metastasectomy for testicular germ cell tumors: a 28-year experience. Ann Thorac Surg. 1998;66:1709-14.

19. Agero AL, Dusza SW, Benvenuto-Andrade C, Busam KJ, Myskowski P, Halpern AC. Dermatologic side effects associated with the epidermal growth factor receptor inhibitors. J Am Acad Dermatol. 2006;55:657-70.

20. Motzer RJ, Amsterdam A, Prieto V, Sheinfeld J, Murty VV, Mazumdar M, et al. Teratoma with malignant transformation: diverse malignant histologies arising in men with germ cell tumors. J Urol. 1998;159:133-8.

21. International Germ Cell Cancer Collaborative Group. International Germ Cell Consensus Classification: a prognostic factor-based staging system for metastatic germ cell cancers. J Clin Oncol. 1997;15:594-603.

22. Andre F, Fizazi K, Culine S, Droz J, Taupin P, Lhomme C, et al. The growing teratoma syndrome: results of therapy and long-term follow-up of 33 patients. Eur J Cancer. 2000;361:1389-94.

23. Putra LJ, Lawrentschuk N, Ballok Z, Hannah A, Poon A, Tauro A, et al. 18F-fluorodeoxyglucose positron emission tomography in evaluation of germ cell tumor after chemotherapy. Urology. 2004;64:1202-7.

24. Kollmannsberger C, Oechsle K, Dohmen BM, Pfannenberg A, Bares R, Claussen CD, et al. Prospective comparison of [18F]fluorodeoxyglucose positron emission tomography with conventional assessment by computed tomography scans and serum tumor markers for the evaluation of residual masses in patients with nonseminomatous germ cell carcinoma. Cancer. 2002;94:2353-62.

25. Sugimura J, Foster RS, Cummings OW, Kort EJ, Takahashi M, Lavery TT, et al. Gene expression profiling of early- and late-relapse nonseminomatous germ cell tumor and primitive neuroectodermal tumor of the testis. Clin Cancer Res. 2004; $10: 2368-78$. 